\title{
Comparing the use of modern and traditional building design systems in construction projects
}

\author{
M.Sc. Yasser Sahib Nassar* \\ College of physical Planning, University of Kufa, Najaf, Iraq \\ *Author of Correspondence: Yasser Sahib Nassar, yasirs.radhi@uokufa.edu.iq
}

\begin{abstract}
Any construction project through several stages, starting from the feasibility study stage to the project delivery stage, as the most critical stage that must be focused on is the design stage. It was essential to adopt modern and advanced programs at the design stage to avoid problems and claims between the employer and the contractor due to changes and errors that occur in the project-design process. BIM is one of the modern technologies with many benefits that can be used to solve these errors and obstacles. This research aims to clarify the effectiveness of introducing the BIM system in the design stage of the construction building by comparing it with traditional CAD systems. In this research, ten different actual projects were studied in the architectural design stage to be used in the comparison process between BIM and CAD systems. The researcher reached a set of results, including that introducing the (BIM) in the architectural and structural design stage can reduce the time required to produce design documents by up to $(67.6 \%)$. This study is helpful for all governmental and private design companies and encourages decision-makers to use the BIM system.
\end{abstract}

Keywords: BIM System, CAD system; Design phase; Residential buildings; Construction Projects.

\section{Introduction}

The construction building is one of the main pillars of the Iraqi national economy. This construction building includes all the activities of building major infrastructure projects and real estate, maintenance of any of the existing structures and consist types stakeholders' government such as real estate developers, professionals, academics, contractors, consultant, and government officials. Construction building faces a decline in the rate of productivity when compared to other sectors, which is mainly due to poor planning, coordination and poor communication between the project parties.

Therefore, the research will study the extent to which quality of construction design has improved in the construction building through building information modeling systems. In many areas, visualization is an effective tool for understanding and enhancing defecult relationships and systems. This is especially true concerning understanding complex spatial relationships, such as construction structures (1). Some consider the misperception of project information as the biggest problem in the planning and construction of building projects, "the devil is in the details". An engineering project that, if not entirely conceived, understood, and communicated, cannot be adequately presented in contract documents, and this causes problems. In addition, disagreements during the construction phase (2). 
Errors and deficiencies in project documents usually cause unexpected field expenses, delays, and legal litigations between the multi parties to the building (3).

Building information modeling is a promising technique that provides many solutions to the problems above associated with the unique nature of the construction building. It is a technical procedural model that appeared in the "Architecture, Engineering and Construction" projects after the paper preliminary drawing and design with the help of CAD (4). While CAD has evolved from 2D to 3D, 4D, and even 5D, including not only 3D geometry but also the time as the fourth dimension and cost as the 5D (5). We find that BIM includes all of this. In addition to more specific information on the various elements associated in the building, such as wall types, voids, air handling units, geospatial data, and circulation areas (6). BIM simulates a construction project in a virtual environment. A virtual build is where you can build, test, and make modifications to a project before it becomes real. As default, errors generally do not have serious consequences provided; they are identified and addressed early enough to avoid them when working in the field. Many construction companies have applied similar approaches to their projects, although critics claim that simulation is only helpful for iterative production processes, and construction is unique. However, suppose there is only one opportunity to get something done correctly. In that case, it will be more beneficial to prepare well for that opportunity virtually, thus reducing the inherent risks and increasing the chances of success and effectiveness (2). Figure 1 represents the development stages of BIM processes and tools compared to a CAD system (7).

Figure 1. BIM development stages

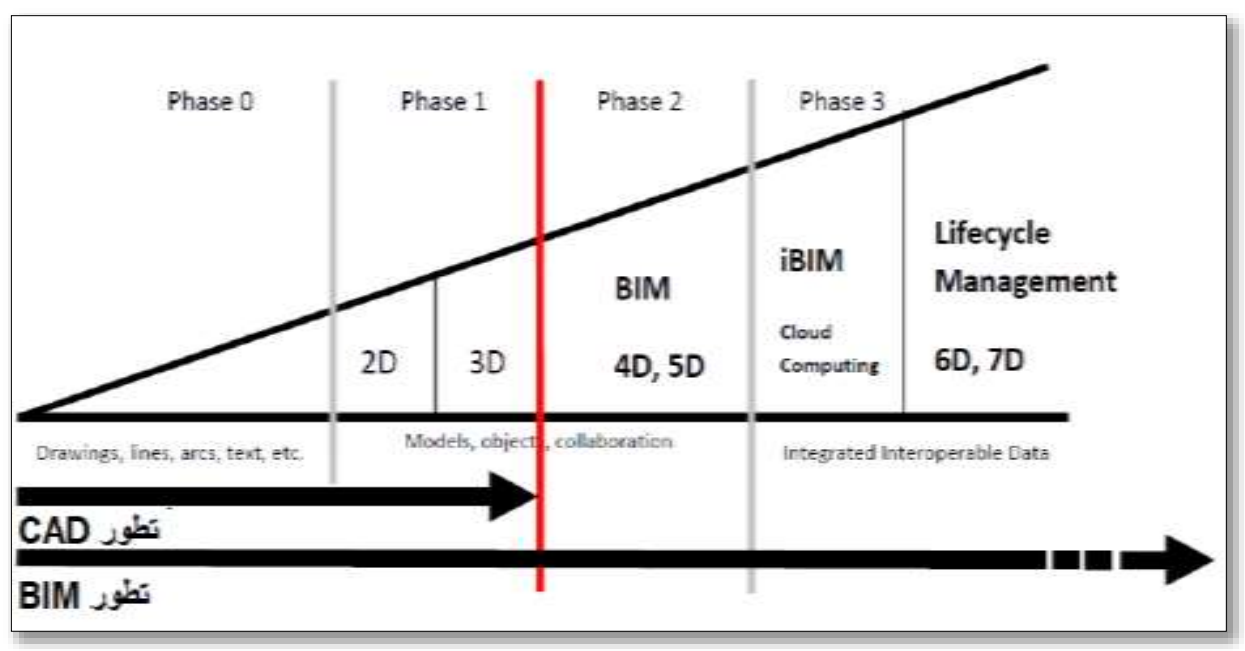

It changes the essential documentation used in construction from a human-readable one to a new machinereadable representation. 3D parametric systems facilitate constructing a virtual digital building that contains a detailed geometric description of the building (8). Being a single-source model means that all schemas generated from it are guaranteed to be identical. Quantity reporting cost estimating, and scheduling can automated with great accuracy (3). In this way, it was possible to overcome the obstacle of fragmented information impeding the process of exchanging this information in traditional CAD systems (9). As a result, the designer's attention is focused on design solutions, not technical blueprints automatically extracted by the computer (10). These design solutions are determined at the design stage, which is when customer requirements are defined; construction features and quality standards are defined through procedures, blueprints, and technical specifications (11). Therefore, design is the activity in which the most significant part of the information about the project is defined (3). Building information modeling BIM offers many benefits when used in the design phase, including $(13 ; 12)$ : 
- Generate schemas for any group of objects and at any time in the project directly from the model, which means.

- Significantly reduce the time required to generate schemas manually.

- Calculating quantities and estimating the cost will be faster, easier and more accurate.

- The design changes proposed and implemented in the model will affect all other parts of the building.

- A Complete and integrated understanding of modeled objects.

\section{Importance and Objectives of Research:}

It is noted that the local construction industry suffers in particular at the design stage from negatives that significantly affect performance, including:

- Design errors.

- Inconsistencies in information between different technical documents.

- Making many modifications throughout the design process, and the difficulty of making those modifications, especially in the advanced stages.

- Lack of or lack of coordination between the various disciplines working in the project.

- Late delivery.

- $\quad$ Ignoring the sequence of construction stages and mixing these stages

BIM offers many advantages that can contribute to solving a large percentage of these problems. Considering that the adoption of information modeling system technology is increasing rapidly worldwide (15; 14), it was necessary to search for how this technology can be introduced to the local construction industry.

\section{Research Methods and Materials:}

in this study, has been Multiple case studies of actual projects the design stage only, using CAD and BIM programming. Where did identify indicators that would constitute the quantitative value of the work resulting from the design process, these indicators were adopted as a basis for the comparison process between CAD and BIM programming.

Collected the data were by selecting samples of projects belonging to the category of residential buildings only. There are ten samples, half of which were completed using CAD and the other half-using BIM. Although two cases of buildings cannot be identified according to two different design systems, it was taken into account that the total amount of effort required to produce the design documents for both groups is very close, depending on the nature of the buildings and based on the designers' opinion in this regard. It was taken into account that the designers should be at the same level of professionalism in using both systems (which is a high degree of professionalism). As for studied projects, their designs were distributed among the consulting offices at the University of Baghdad and the University of Kufa, in each of the governorates of Najaf and Holy Karbala. All the indicators that were adopted as a basis for the measurement process in each project were recorded. Accordingly, an analysis of the results of the measurements measured according to the computational analysis methods was conducted by defining several mathematical factors that gave a clear picture of the results and content of the measurement process.

\section{Indicators used in the comparison process}

The quantitative indicators in the comparative measurement process between the two systems, CAD and BIM, will be adopted to cover the main documentary outputs of the design process: plans, quantities, and specifications. Depending on the impact of technical BIM on the design process, these indicators should cover the functions of visualization and modification. Based on the previous argument, it is possible to identify the indicators based on the comparison process. Table 1 shown with the comparative measurement of each: 
Table 1. Shown the comparative measurement

\begin{tabular}{ccc}
\hline S.N & Pointer & Comparative Measurement \\
\hline 1 & Execution of operational plans & Time to a complete executive plans \\
\hline 2 & Quantification and cost & Quantification time and cost \\
\hline 3 & Drafting technical specifications & Technical specifications setting time \\
\hline 4 & Better visualization and a & Time to complete the explanatory \\
& clearer understanding & and marketing plans \\
\hline 5 & Make and include modifications & Time to make adjustments \\
\hline
\end{tabular}

\section{Description of the selected cases for the study}

The case study was conducted on ten samples of residential buildings. Half has done according to CAD technology (using AutoCAD program) and Half to BIM technology (using Rivet program). Table 2 describes each of them:

Table 2. Selected Construction Projects

\begin{tabular}{clccc}
\hline S.N & \multicolumn{1}{c}{ Project Name } & $\begin{array}{c}\text { Floor of } \\
\text { Area }\end{array}$ & $\begin{array}{c}\text { number of } \\
\text { floors }\end{array}$ & $\begin{array}{c}\text { User design } \\
\text { system }\end{array}$ \\
\hline $\mathbf{1}$ & Internal Departments Project for Students (A) & 550 & 4 & CAD \\
\hline $\mathbf{2}$ & Project of the internal departments for female students (B) & 550 & 4 & CAD \\
\hline $\mathbf{3}$ & Building a five-star hotel & 375 & 3 & CAD \\
\hline $\mathbf{4}$ & Building a private hospital in Al-Saad neighborhood & 650 & 5 & CAD \\
\hline $\mathbf{5}$ & A multi-purpose building. & 650 & 5 & CAD \\
\hline $\mathbf{6}$ & Listed halls of the University of Kufa & 350 & 5 & BIM \\
\hline $\mathbf{7}$ & Building a medical clinic - Najaf Health Department & 500 & 5 & BIM \\
\hline $\mathbf{8}$ & Building a commercial mall Al Rawan Street - Najaf Al-Ashraf & 750 & 3 & BIM \\
\hline $\mathbf{9}$ & Building a commercial mall Al-Ghadeer Street & 640 & 5 & BIM \\
\hline $\mathbf{1 0}$ & Presidency of the Islamic University of Najaf & 315 & 6 & BIM \\
\hline
\end{tabular}

\section{Data Collection}

The method used to collect data was direct measurements of the completion times of design documents by CAD and BIM systems users. The design documents for each of the study cases were divided into categories, followed by each of the indicators used in the comparison process. Table 3 shows the outputs of the design process and their distribution over the comparative measurements:

Table 3. Design documents and their distribution according to comparative measurements

\begin{tabular}{cll}
\hline S.N & Comparative Measurement & Design Documents \\
\hline 1 & Time to complete executive plans & $\begin{array}{l}\text { Plans (ground - repeated - basement - roof), Sections } \\
\text { (two perpendicular sections), Facades (four faces), } \\
\text { Concentration tables (concentration tables) }\end{array}$ \\
& & Bills of quantities and cost \\
\hline 2 & Quantification time and cost estimation & Technical Specifications \\
\hline 4 & Technical specifications setting time & Time to complete the explanatory and \\
& marketing plans & $\begin{array}{l}\text { Mass view before cladding Full Architectural } \\
\text { Perspective with Render }\end{array}$ \\
\hline & Time to make adjustments & The times required to complete all documents related to each comparative measurement have been \\
collected to obtain the time for this measurement for each case. Then, the times belonging to the same height were
\end{tabular}


in all the study cases belonging to one design system to get the total times belonging to each comparative measure and for all the study cases belonging to the CAD and BIM design systems.

It should be noted here the method in which the comparative measurement of the adjustment time was made. Due to the impossibility of identical or even closeness in the modification process for the documents produced in each of the two design systems, the modification times of the CAD system documents were measured only. For each modification process, the time required to complete. As an estimated time to complete this modification using the BIM system, it is done on only one document among the affected documents to complete the modification process according to the BIM system. The rest of the documents are automatically updated.

\section{Results and Discussion:}

Depending on the method mentioned above of data collection, we can summarize the results of the comparative measurement process applied to studied samples of projects in both CAD and BIM design systems in Table 4:

Table 4. Total time for completion of the design documents for studied projects (hours)

\begin{tabular}{cccc}
\hline S.N & Comparative Measurement & CAD & BIM \\
\hline 1 & Time to a complete executive plans & 65.5 & 21.1 \\
\hline 2 & Quantification time and cost estimation & 69.3 & 23.00 \\
\hline 3 & Technical specifications setting time & 55.55 & 16.50 \\
\hline 4 & Time to complete the explanatory and marketing plans & 48.00 & 15.30 \\
\hline 5 & Time to make adjustments & 24.30 & 9.20 \\
\hline & Sum & $\mathbf{2 6 2 . 6 5}$ & $\mathbf{8 5 . 1}$
\end{tabular}

It is evident from Table 4 that the significant savings caused by the use of BIM in the times of completion of the various design documents of the project. To shed light on the different aspects of these results, we will define a set of arithmetic factors, and we will use the following terms in this way:

DAD: Completion time according to CAD for one measurement.

> BIM: Completion time according to BIM for a single measure.

$>$ BIM/CAD: The ratio of completion time according to BIM to completion time according to CAD for one action.

$>$ BIMG: temporal gain in the use of BIM for a single measurement. It gives a relationship. BIM/CAD 1= BIMG or With the relationship: $(\mathbf{C A D}-\mathbf{B I M}) / \mathbf{C A D}=\mathbf{B I M G}$.

$>$ TCAD: Total completion times according to CAD for all measurements.

$>$ TBIM: The sum of the completion times according to BIM for all measurements.

$>$ CAD/TCAD: The ratio of completion time according to CAD for one measurement to the total completion times according to CAD for all sizes.

$>$ BIM/TCAD: The ratio of completion time according to BIM for one measurement to the total completion times according to CAD for all sizes.

$>$ BIMPG: Time gain in using BIM for one measurement for all measurements. It is given by BIM/TCADCAD/TCAD=BIMPG or as related: BIMPG=BIMG.CAD/TCAD.

Table 5 shows the corresponding values for the data analysis process according to the previously defined mathematical factors, noting a slight change for some deals from their mathematical equation, depending on the accuracy of displaying the results: 
Table 5. Statistical analysis of the completion times of the design documents for studied projects.

\begin{tabular}{clccccccc}
\hline S.N & Comparative Measurement & CAD & BIM & $\begin{array}{c}\text { BIM/C } \\
\text { AD }\end{array}$ & BIMG & $\begin{array}{c}\text { CAD/T } \\
\text { CAD }\end{array}$ & $\begin{array}{c}\text { BIM/T } \\
\text { CAD }\end{array}$ & BIMPG \\
\hline 1 & $\begin{array}{l}\text { Time to complete executive } \\
\text { plans }\end{array}$ & 65.5 & 21.1 & $\% 32.21$ & $67.79 \%$ & $\% 24.94$ & $\% 8.03$ & $\% 16.90$ \\
\hline 2 & $\begin{array}{l}\text { Quantity calculation time } \\
\text { and cost estimation }\end{array}$ & 69.3 & 23 & $\% 33.19$ & $\% 66.81$ & $\% 26.38$ & $\% 8.76$ & $\% 17.63$ \\
\hline 3 & $\begin{array}{l}\text { Technical specifications } \\
\text { setting time }\end{array}$ & 55.55 & 16.5 & $\% 29.70$ & $\% 70.30$ & $\% 21.15$ & $\% 6.28$ & $\% 14.87$ \\
\hline 4 & $\begin{array}{l}\text { Time to complete } \\
\text { explanatory and marketing }\end{array}$ & 48.55 & 15.3 & $\% 31.88$ & $\% 68.13$ & $\% 18.28$ & $\% 5.83$ & $\% 12.45$ \\
\hline 5 & Time to make adjustments & 24.3 & 9.2 & $\% 37.86$ & $\% 62.14$ & $\% 9.25$ & $\% 3.50$ & $\% 5.75$ \\
\hline$\quad$ Sum & 262.7 & 85.1 & & & $\% 100$ & $\% 32.4$ & $67.6 \%$ \\
\hline
\end{tabular}

The computational analysis of data on completion times for design documents gives a good idea of the extent to which the BIM system contributes to reducing the time required to produce these documents. In the following, we will highlight the picture in which achieved this was by creating a set of illustrative charts showing the extent of the contribution made by each element of comparative measurements.

Figure 2 illustrated the most significant time gain in using BIM was setting the technical specifications, which achieved a time gain of (70.30\%) (Error! Unknown Switch Argument). As for the lowest income, it was for the time to complete the modifications, which amounted to $(62.14 \%)$ and should note that part of this time is not subject to human activity in using the technology, but instead is due to the time taken by the rendering process, which is the same time required in both CAD and BIM systems.

Figure 2. Time gain in using BIM for each measurement.

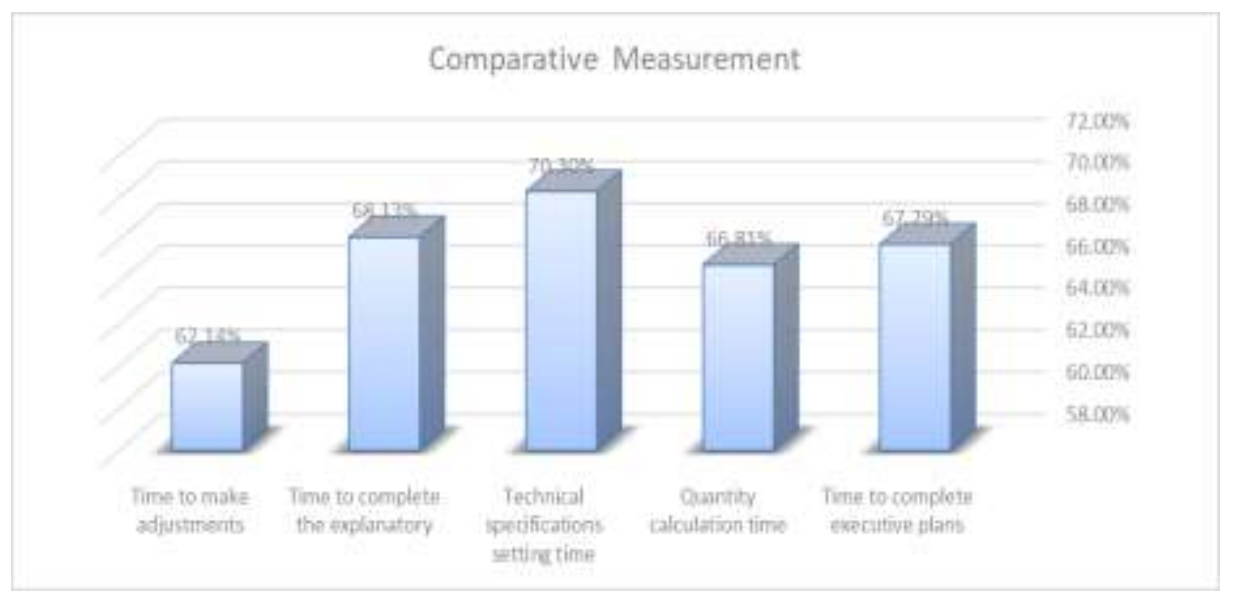

According figure (3) the CAD system the time for calculating quantities and estimating the cost ranked first among the rest of the times, with its contribution $(26.38 \%)$ of the total time required to complete the design documents according to the CAD system. And at the same time, the time of making the amendments ranked last, with a contribution of $(9.25 \%)$ of the total time. 
Figure 3. Distribution of contribution percentages for each measurement

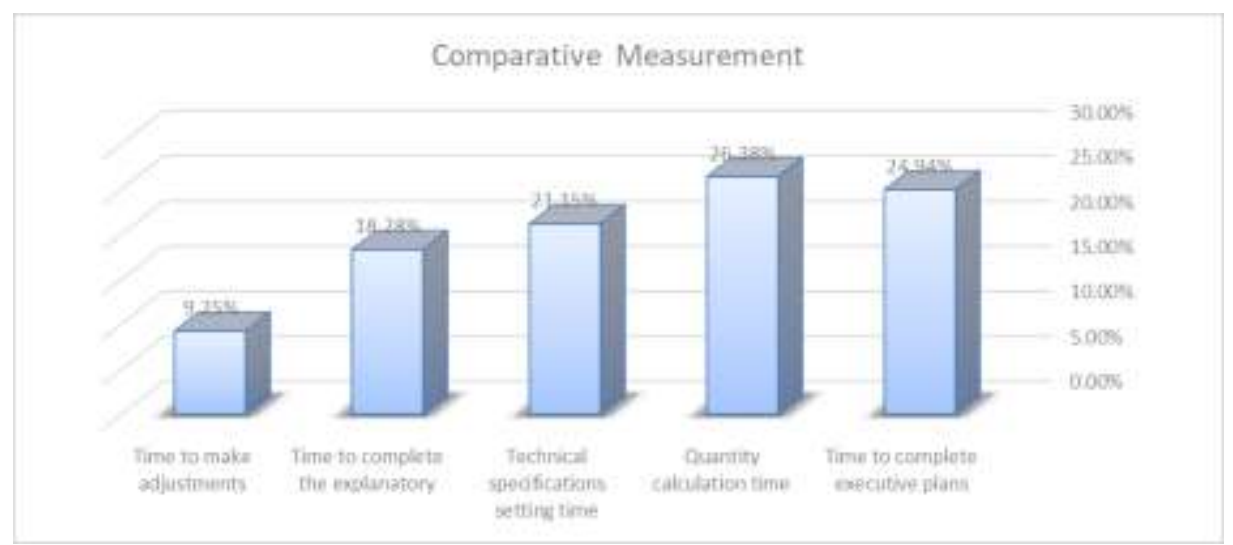

Figure 4 shows that calculating quantities and estimating the cost occupies the highest percentage of contribution $(8.76 \%)$ of the total time required to complete work documents according to the CAD program. At the same time, the time of making adjustments ranked last, with a contribution of $(3.5 \%)$ of the traditional total time according to CAD.

Figure 4. The BIM completion time relative to traditional CAD document production time

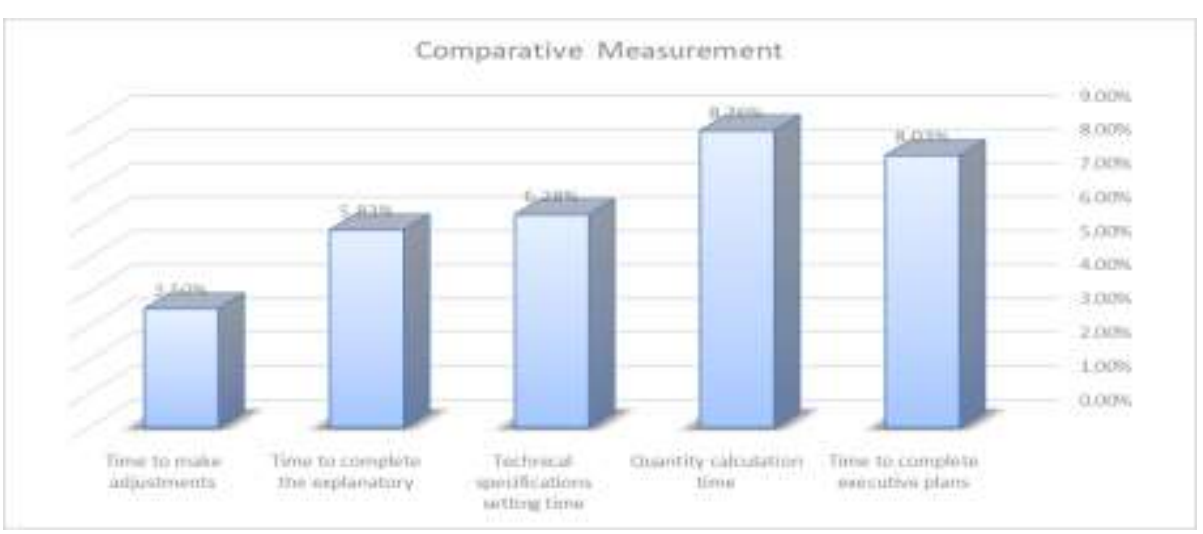

Finally, when using BIM, we find that the time for calculating quantities and estimating the cost worked to reduce the most significant amount of the overall design effort expended to produce the entire design documents according to the CAD system, as this reduction reached a percentage (17.63\%) as shown in Figure 5. In contrast, the time for making modifications took place. It ranks last in this disadvantage by reducing the entire design effort expended according to the CAD system by (5.75\%). When collecting these last reductions for all times according to the BIM system, we find that this technique has reduced the production time of design documents according to traditional CAD methods by (67.6\%). It is the total productivity gain obtained from the contribution of the BIM system in the production of these design documents. Although the results we obtained were based on quantitative measurements, transparent methodology, and specific influences, several points should be noted when discussing these results. Here are the highlights. 
Figure 5. BIM contribution to reducing the time of traditional design documents according to CAD

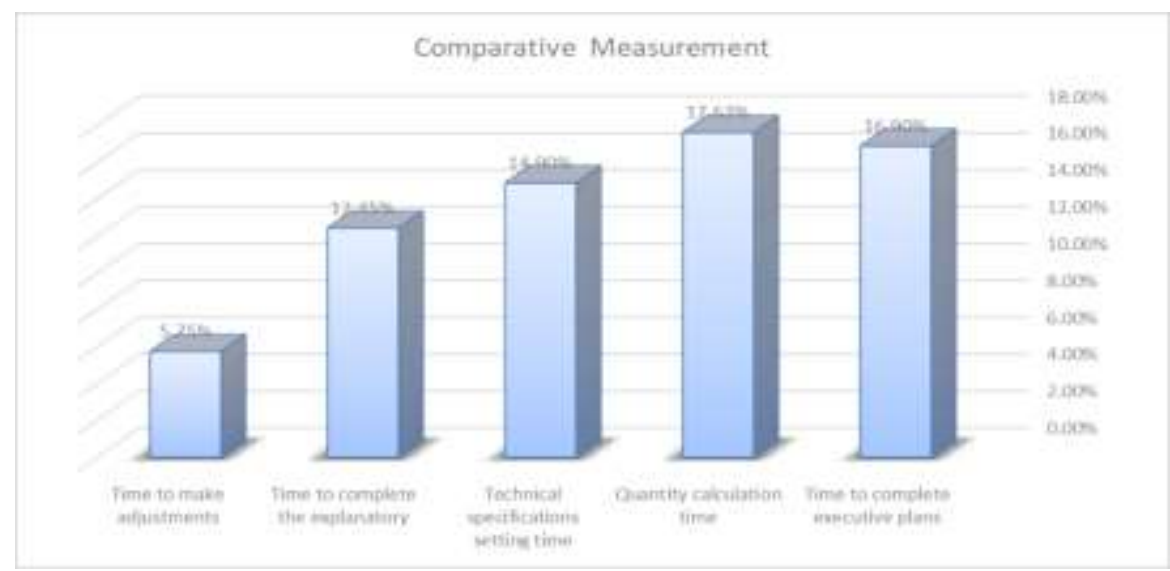

\subsection{Study Samples}

Samples of the studied projects belong to the category of residential buildings, and the study was limited to this category for two reasons main:

1. The similarity like buildings allows a fair comparison between the application of CAD and BIM systems for similar structures in terms of the design effort expended in producing documents.

2. The scarcity of buildings of a private nature designed using BIM due to the recent emergence of this technology in the local labour market, and its use is limited to individual initiatives.

The possibility remains that the experimental results when using BIM in projects of a unique nature differ from what was reached in this research, despite our conviction that the technical tools available in the engineering labour market currently in the use of BIM have earned a degree of maturity that eliminates concern about the difficulty of The suitability of this technique for projects of a unique nature.

\subsection{BIM contribution to the design process}

According to the previous study, the percentage that the BIM system contributes to reducing document production time, amounting to (67.6\%), would constitute an excellent incentive for any company to start adopting this technology. The degree of professionalism in using the technical tools of the BIM system plays a central role in reaping the benefits offered by this system. It controls the percentage reduction of effort involved in producing design documents that can be accessed using BIM.

However, it is a mistake to think that the entire design process will be reduced by such a large percentage when the BIM system is adopted. The design process contains human activities in which the technician does not use any computer system. These activities may include rudimentary paper designs or mental tests of proposed design alternatives, private discussions among team members, general meetings with management, or communication with other project stakeholders. Still, even these activities can be positively affected by the use of the BIM system.

\subsection{Workload shift according to specialization and experience}

The effort to produce documents by traditional CAD methods using BIM is due to the significant improvement offered by the latter system in this field. As a result, the effort expended will shift towards the model building, which requires more design expertise than document production. This will reduce the number of less experienced crewmembers, and those working in document production favors the more experienced personnel who will build the model. 


\subsection{Technology Maturity}

The comparison results obtained in this study indicated the validity of the hypotheses presented about the benefits offered by BIM at the design stage. Although the concept of BIM technology appeared not so recently(16), its entry into the market at the commercial production level did not occur until recently, mainly due to the increase in the capabilities of personal computers (17), which provided the possibility for the emergence of this technology, which is classified as the next generation From computer-aided design systems (8). In addition to maturity reached by its technical tools in the design phase. Despite the emergence of a technical concept, it offers a greater breadth of suitability for different design requirements (18).

\section{Conclusions and Recommendations:}

\subsection{Conclusions:}

In the following, we will present a set of conclusions that can explore through the findings of research and the discussion on it.

\subsubsection{Moving from CAD to BIM}

The construction projects have an effective amount of inertia that tends to remain the same (19). BIM is slowly but surely finding its way into design firms around the world. Despite well-established traditional CAD practices, competition and a sense of being late to a winning formula have become the primary motivators, among others, behind the decision to implement the new technology everywhere. The question about whether or not to implement this new technology has changed to how to implement it (20). BIM delivers a significant improvement in productivity in the design process. When combined with the economic benefits of BIM in the short and mediumterm, this improvement will continue to drive BIM forward (21). The local construction industry should be aware of this movement and seek to realize it before too late.

\subsubsection{The Cultural and Technical risk of moving from CAD to BIM}

Technology will affect the company's balance it enters into, whatever role it plays in the construction industry. The organization's size does not matter, and it will experience transformation, confusion, and disobedience. For example, it is not uncommon for technology initiatives to fail due to user resistance due to culture. The phrase, "This is not how we do things here," is not surprising. So change is naturally resisted unless a motivating circumstance or cultural change can overcome the resistance (22). In addition, here emerges the role of the enlightened and determined management in following the transition process in all its details until the technology is consolidated in the company's work. As (Hammod 2008) emphasizes, unexpected changes and unintended repercussions will occur over time in any organization. Touch one of the foundation items, and the other things will start spinning in different directions. It is nearly impossible to change one element without affecting the rest. Over time and lack of follow-through, the response to change can become breaking points and confusion, or opportunities for innovation and transformation (22).

\subsubsection{Changes carried by the transition from CAD to BIM}

Moving to adopt BIM instead of CAD brings with it many changes in construction practices (23). BIM system is not a thing or a type of software but rather a human activity that involves sweeping changes in the construction projects process (3). It is leading the construction industry towards a model-based approach, away from a two-dimensional process (15). However, the most significant changes are those that will result from BIM at the strategic level and change the nature of the company itself. Can feel some of these changes in: 
1. Changing the quantity of work:

The time saving is provided by BIM systems in the design stage will reduce the duration of the design stage. This allows the company to accept a larger volume of design work while maintaining its technical staff. As for the other option, it is to restructure the company to match the size of the technical staff with the amount of work available.

2. Changing the quality of the productive work:

As we found earlier, BIM involves raising the quality of practical work in terms of clarity or consistency. This will have other repercussions in later phases of the project (the implementation phase and the operation and maintenance phase).

3. Changing the competitive situation in labour market:

The company's fulfilment of its obligations towards customers within a shorter time and with a higher quality of work will reflect positively on the company's reputation, thus achieving a better competitive position in the labour market. "Smart Market Report 2008" found that BIM users expect to increase their investment in it in the face of an economic recession. With growing recognition of the benefits of BIM, experienced users are achieving greater productivity, improved communications, and a competitive margin in job offers, thus distinguishing themselves from those who have not yet embraced the technology. "Ibrahim" believes that BIM is gaining more ground each year in the professional practice of architecture. Accordingly, we expect that more graduates will use such applications in the same way that we hope that almost everyone will be familiar with traditional CAD programs (24).

\subsection{Recommendations:}

Below we offer a set of recommendations for those involved in the construction industry, including managers, investors, legal professionals, and a CAD.

\subsubsection{Managers: Don't be late in making a decision}

Many company managers tend to be comfortable with their company's situation as long as it gets the work done, "if it doesn't break, leave it as is." This phrase is no longer valid in the era of modern technologies. Taking initiatives to develop work according to a calculated plan has become one of the basics of continuity in a changing market. The early adopters of company managers can reap the benefits of adopting BIM technology in architectural design. In contrast, the late ones are likely to find their company after a short period in a difficult competitive position that may affect their work in the labour market.

\subsubsection{Investors: the need for investments and changes}

The implementation of BIM systems requires investments and changes in the labour market and in how construction companies operate. Moreover, investment is needed in training students in concepts and familiarity with this type of tool. The anticipated change relates to innovation and competitiveness in the building environment, where architects and engineers play a critical role in applying a CAD work.

\subsubsection{Legal: Introduce contractual terms for the use of BIM}

With the development of BIM technology, many nodal clauses need to be carefully taken into account. Unfortunately, the novelty of BIM. Please leave us with more questions than answers for now. The various parties involved in the project must weigh these questions and, when applicable, reach understandings that are mentioned inappropriate contractual documents. The adoption of new technology such as BIM, which carries with it many changes in the course of operations, makes it necessary to research the development of new contract clauses between project participants, including companies providing design services. 


\section{References}

[1] SHEN, Z.; ISSA, R. R. "Quantitative evaluation of the BIM-assisted construction detailed cost estimates". ITcon, Vol. 15, 2010, 234-257.

[2] KYMMELL, W. "Building information modeling: planning and managing construction projects with 4D CAD and simulations". McGraw-Hill New York, 2008, p 270.

[3] EASTMAN, C.; TEICHOLZ, P.; SACKS, R.; LISTON, K. "BIM handbook: a guide to building information modeling for owners, managers, designers, engineers, and contractors". 2nd ed., Wiley, 2011, p 626.

[4] SUCCAR, B. "Building information modelling framework: A research and delivery foundation for industry stakeholders". Automation in Construction, Vol. 18, No. 3, 2009, 357-375.

[5] KRAUS, W.; WATT, S.; LARSON, P. "Challenges in estimating costs using building information modeling". AACE International Transactions, 2007, 11-13.

[6] GSA. GSA "BIM Guide Overview". U.S. General Services Administration, 2007, p 32.

[7] DINESEN E., THOMPSOM., 2010 . "Constructing the business case Building information modeling"., ST., British Standards Institution, UK.

[8] LEE, G.; SACKS, R.; EASTMAN, C. M. "Specifying parametric building object behavior (BOB) for a building information modeling system". Automation in construction, Vol. 15, No. 6, 2006, 758-776.

[9] FU, C.; AOUAD, G.; LEE, A.; MASHALL-PONTING, A.; WU, S. "IFC model viewer to support model application". Automation in Construction, Vol. 15, No. 2, 2006, 178-185.

[10] BIRX, G. W. "Getting started with Building Information Modeling". The American Institute of Architects-Best Practices, 2006.

[11] ALARCON, L. F.; MARDONES, D. A. "Improving the design-construction interface". Proceedings of the 6th Annual Meeting of the International Group for Lean Construction, 1998.

[12] WINBERG, A.; DAHLQVIST, E. "BIM-the Next Step in the Construction of Civil Structures". Master's thesis; Royal Institute of Technology, Stockholm, Sweden, 2010.

[13] SARSHAR, M.; CHRISTIANSSON, P.; WINTER, J. "Towards virtual prototyping in the construction industry": the case study of the DIVERCITY project. World It Conference For Design And Construction, Langkawi, Malaysia, 2004, pp 581-588.

[14] Smart Market Report. "Building Information Modeling (BIM)". McGraw-Hill Construction, 2008.

[15] Smart Market Report. "The Business Value of BIM in Europe". McGraw-Hill Construction, 2010. [16] WONG, A. K.; WONG, F. K.; NADEEM, A. "Government roles in implementing building information modelling systems: Comparison between Hong Kong and the United States". Construction Innovation: Information, Process, Management, Vol. 11, No. 1, 2011, 61-76.

[17] IBRAHIM, M.; KRAWCZYK, R.; SCHIPPORIET, G. "CAD smart objects: potentials and limitations". Education and Research in Computer Aided Architecture Design in Europe ECAADe, Vol. 21, 2003, 547-552.

[18] AZHAR, S.; NADEEM, A.; MOK, J. Y.; LEUNG, B. H. "Building Information Modeling (BIM): A new paradigm for visual interactive modeling and simulation for construction projects". Proc., First International Conference on Construction in Developing Countries, 2008, pp 435-446.

[19] RISCHMOLLER, L.; FISCHER, M.; FOX, R.; ALARCON, L. "4D Planning And

Scheduling (4D-PS): Grounding Construction IT Research In Industry Practice". Proceedings of the Construction Information Technology CIB w78 International Conference-IT in Construction in Africa, Mpumalanga, South Africa, 2001, pp 34-1 -34-11. 
[20] IBRAHIM, M. "To BIM or not to BIM, This is NOT the Question". Communicating space (s) 24th ecaade conference proceedings, 2006, pp 262-267.

[21] ASHRAE. "An Introduction To Building Information Modeling (BIM)", 2009, p 27.

[22] HAMMOND, D. "The BIM Balancing Act". Journal of Building Information Modeling, Fall 2008 edition, 2008, 16-21.

[23] LU, W. W.; LI, H. "Building information modeling and changing construction Practices". Automation in Construction, Vol. 20, No. 2, 2011, 99-100.

[24] IBRAHIM, M. "Teaching BIM, What Is Missing?" 3rd Int'1 ASCAAD Conference on Em 'bodying Virtual Architecture, 2007. 